\title{
How the pandemic taught us to turn smart beta into real alpha
}

\author{
Christopher Kantos $^{1}$ (D) Dan diBartolomeo ${ }^{1}$
}

Revised: 22 October 2020 / Accepted: 23 October 2020 / Published online: 17 November 2020

(c) Springer Nature Limited 2020

\begin{abstract}
The ongoing COVID-19 pandemic has strongly reminded equity investors that rare but extreme events occur from time to time. At the individual firm level, such events also impact the likelihood of bankruptcy, a feature that is not well represented in the traditional Capital Asset Pricing Model. This paper presents a functional form for equity asset pricing that is realistic, and reconciles the observed high equity risk premium with the observed lower than expected slope of the Security Market Line. Most importantly, we will demonstrate how including the potential for such large events changes traditional views of equity returns and the known factors that contribute to those returns. On the basis of empirical examination of a dataset stretching over 30 years without survivorship bias, we conclude that when the probabilities of rare extreme events are considered, strategies that focus on "alpha" (risk adjusted return) as defined in Jensen (J Finance 23(2):389-416, 1967) are structurally superior to "smart beta" strategies that seek to outperform a market index benchmark.
\end{abstract}

Keywords Alpha $\cdot$ Asset pricing $\cdot$ CAPM $\cdot$ Equity risk $\cdot$ Factor returns $\cdot$ Smart beta

\section{Introduction}

The ongoing COVID-19 pandemic has strongly reminded equity investors that rare but extreme events occur from time to time. These events represent periods of increased volatility and in some cases very negative market returns for extended periods. At the individual firm level, such events also impact the likelihood of bankruptcy, a feature that is not well represented in the basic asset pricing literature. This paper presents a contribution to the financial literature by proposing a functional form for equity asset pricing that is both realistic and can be easily tested with a widely used data set extending over 30 years. Most importantly, we will examine how including the potential for such large events changes traditional views of equity returns and the known factors that contribute to those returns. By incorporating the probability of such rare events in equilibrium factor models, we conclude that strategies that focus on "alpha" (risk adjusted return) as defined in Jensen (1967) are structurally superior to "smart beta" strategies that attempt to outperform an equity index by active exposure to one or more recognized factors.

Christopher Kantos

chris@northinfo.com

1 Northfield Information Services, Inc., Boston, MA, USA
There are several historical features of equity market asset pricing that we will seek to explain. The most obvious is that the equity risk premium (return of equities minus the risk free rate) is widely considered to be unexpectedly high. This has led some researchers to argue that long-term investors should always be fully invested in equities (e.g., Siegel 2014). At the same time, there has been widespread criticism of the mostly commonly known asset pricing model, the CAPM (Sharpe, 1964) as failing to describe equity asset returns. The amount of return associated with low beta stocks versus high beta stocks seems inconsistent with the Sharpe version of the CAPM. There is also a massive literature of "factor anomalies" that describe persistent excess returns associated with security attributes in violation of the Efficient Markets Hypothesis (Fama, 1970). Among the equity characteristics that have broadly documented associations with abnormal returns are "value," "momentum," "size" and "low volatility."

For the purposes of this paper, we will use certain semantic conventions in the way we describe factor returns. Our first distinction is the difference between "excess return" and "alpha." We will use "excess return" for return outcomes that outperform some appropriate passive benchmark. We will use "alpha" to describe investment outcomes that outperform some measure of expected returns, where the magnitude of the expectation is associated with a chosen 
metric for risk. It should be noted that our use of alpha term accepts the possibility that the chosen metric for risk may account for multiple systematic effects (i.e., factors) rather than be limited to the single factor structure of the early CAPM literature, which implies that alpha could arise only from security selection within the opportunity set afforded by idiosyncratic risks. Alternatively, one could limit the use of "alpha" to outcomes from idiosyncratic opportunities and use another term such as "risk premia" to describe return outcomes associated with non-beta factors. Our other semantic distinction is whether we estimate the return outcomes in a simple or orthogonal fashion. Factor outcomes can be simple. For example, we can compare returns on a large cap portfolio and a small cap portfolio, as a "size" factor. However, those two portfolios will have a lot of other differences (e.g., average P/E) so we can't be sure that any observed return differences actually arise from "size." Alternatively, statistical techniques can be used to control for correlated variables so that we can attribute pure return outcomes to particular factors. We will always refer to orthogonal values so we are describing returns associated with factors on a ceteris paribus basis (assuming all else equal).

\section{The capital asset pricing model, critiques, and variations}

Inclusive of alpha, the canonical Capital Asset Pricing Model (Sharpe, 1964 and Jensen, 1968); is expressed as:

$R_{i t}=R_{f}+b_{i}\left(R_{m t}-R_{f}\right)+\alpha_{i t}$

where

$R_{i t}=$ return on asset $i$ during period $t$

$R_{f}=$ the risk free return

$b_{i}=$ the beta of asset $i$, an index of covariance with the market portfolio

$R_{m t}=$ return on the market portfolio during period $t$

$a_{i t}=$ the unexpected (risk adjusted) return on asset $i$ during period $t$

Over the past half century, there have been numerous papers criticizing the CAPM. The collected set of objections is well summarized in Grinold (1993). These criticisms are both theoretical and empirical. The theoretical critiques argue that there are many unrealistic assumptions embedded into the derivation of the original CAPM. First among these are that the CAPM is a single period model which broadly ignores the impact of the compounding of returns over time. It is also assumed that investors can both lend and borrow at the risk free rate with no limitations on leverage. Other assumptions are that there are no transaction costs and taxes, "beta" values are known rather than estimated, and that all investors agree on the definition of the "market portfolio." The major empirical criticism is that the slope of the "security market line" is far less steep than the expected value in terms of the relationship between beta levels and observed returns. The preponderance of criticism has been in regards to the ability of the CAPM to correctly formulate return expectations, but there has not been wide objection to the legitimacy of beta as a risk measure. After more than half a century, revised versions of the CAPM are still the predominant theoretical framework for equity asset pricing, because no more widely accepted alternative has come forward.

There have been many papers in the finance literature that have tried to explain equity returns by various possible refinements of asset pricing under the CAPM. For example, prominent papers by Frazzini and Pedersen (2011), and Jacobs and Levy (2012) argue that most large investors are legally constrained from borrowing. Such investors must hold high beta stocks to expect higher returns, thereby causing the high beta stocks to be overpriced relative to low beta stocks. This effect implicitly explains the lack of steepness in the Security Market Line. Similarly, it should be algebraically obvious that if there is a linear relationship between arithmetic returns and risk (as measured by beta in the CAPM), then the expectation of the geometric mean return over multiple periods must have a convex relationship with beta, so the multi-period Security Market Line must actually curve downward at high levels. A derivation of the inflection point appears in diBartolomeo (2013) within a broader discussion of the practicality of the CAPM assumptions. Under the single period assumptions of the CAPM, the market portfolio is optimal (mean-variance efficient). A game theory method for multi-period optimization of a small portfolio with both consumption and transaction costs can be found in Markowitz and van Dijk (2003). Merton (1973) also adds additional terms to the CAPM to account for multi-period outcomes, hedging investor consumption risk, and possible future changes in the investment universe.

Black (1972) proposes a key variation on the original CAPM. He proposes the return on a "zero beta" asset in place of the risk free rate. In effect this change removed the unrealistic assumption that investors could both lend and borrow at the risk-free rate. In this construct, a zero beta asset may have risk (volatile returns) but is uncorrelated with the market portfolio, so the covariance is zero. Since the zero beta asset can be risky (e.g., gold bars), investors will demand that the zero beta return should be a lot higher than the risk free rate, resulting in a much flatter Security Market Line.

$R_{i t}=R_{0}+b_{i}\left(R_{m t}-R_{0}\right)+\alpha_{i t}$ 
where

$R_{0}=$ return on zero beta assets

With some additional assumptions, the CAPM can be mathematically derived from Modern Portfolio Theory (Markowitz, 1952). This means that the CAPM also embeds some of the assumptions of MPT including that the security returns are effectively random walks where portfolio returns are normally distributed and serially uncorrelated. Longterm studies of equity returns such as Dimson et al. (2014) illustrate that this assumption is sometimes contradicted by rare but extreme events. At the global level we might consider World War I, the Spanish Flu pandemic (1918), the 1929 Crash and subsequent Great Depression, World War II, the Global Financial Crisis (2007-2010), and the current COVID-19 pandemic, for a total of six recognized large events over roughly a century. There are numerous example of national financial collapse such as Russia (1917), Germany (1930s) China (1948), Mexico (1982), Russia (1997), Zimbabwe (2008), and Venezuela (2020). Additionally, there have been a couple of short-lived extreme events such as the October 19th, 1987, stock market crash as detailed in diBartolomeo (1998).

\section{Large events and lottery tickets}

One way to reconcile the CAPM with the existence of rare, but large events is to think of investors being long the equity market and a short a lottery ticket where investors may randomly sustain large losses. This idea is similar to the concept of a catastrophe bond in fixed income. Since the extreme events are rare and random, the expectation of the correlation between lottery payoffs and the market is zero. Our short position in lottery tickets therefore has a beta value of zero even though it is very risky. This is conceptually similar to providers of casualty insurers for rare events (e.g., the "names" of Lloyds of London). Barro (2005) and Gabaix (2012) argue that investors are aware of the potential for rare, large losses and demand a high equity risk premium. If the implicit "lottery loss" asset is unavoidably built into an investor's market exposure, this qualifies under Blacks version of the CAPM as the zero beta risky asset. The expectation of rare, large losses implies that the expected distribution of equity market returns will have negative skew and positive excess kurtosis over finite intervals.

A common approach to reconciling return distributions with higher moments when they are assumed to be normal is the method of Cornish and Fisher (1938). Using this method, we adjust the mean return and expected volatility of the market portfolio to account for the effects of skew and kurtosis, fitting the shapes of the two distributions at a prescribed confidence interval (e.g., $P=.99$ ). For example, consider an asset with $8 \%$ expected annual return with an estimated annual volatility of $10 \%$ under the normal distribution assumption. If we assume a $6 \%$ annual likelihood of a $50 \%$ loss, the expected return drops to $5.2 \%$ and effective volatility of this asset goes from $10 \%$ to $23 \%$. It should follow that investors will demand additional return compensation for the lost return and increased risk, increasing the magnitude of the portion of equity risk premium $\left(R_{m t}-R_{f}\right)$ that is attributable to $R_{0 t}$ and reducing the slope of the SML $\left(R_{m t}-R_{0 t}\right)$.

There are three components of the expectation of $R_{0}$. The first is the time value of money, $R_{f}$. The second is the change in the expected mean of the return distribution. In our previous example this is $(8-5.2)=2.8 \%$ The third is incremental return that investors will demand for the increase in effective volatility. We assert that this incremental return demand will be the incremental volatility $\frac{23-10}{K}$, where the $K$ scalar typically has a value of approximately six so the increase in investors required rate of return will be $\frac{23-10}{6}=2.16 \%$ annually. Combining the two effects for our hypothetical case, the effect of including our "short lottery ticket" is $4.96 \%$, a large fraction of typical magnitude of the equity risk premium.

The predominant objective function for investors is "mean-variance" as proposed in Levy and Markowitz (1979). While the properties of any particular mean-variance objective can be mapped to mean-standard deviation using the "chain rule" of calculus, a different and pragmatic approach to the value of the scalar $K$ can be derived from the methodology in Wilcox (2003). In this process, we assume that the investor has chosen their current level of portfolio risk so as to define a "worst case scenario" for loss. From this boundary condition we can infer the mean variance risk tolerance as a scalar function of the current portfolio expected return and volatility. Algebraic simplification leads to the conclusion that for a wide range of situations and asset allocations, the optimal tradeoff parameter between incremental expected return and incremental volatility is typically about one sixth. For example, a $2 \%$ increase in portfolio volatility is reasonably justified by a $.33 \%\left(\frac{2}{6}\right)$ increase in expected return. The method works identically across absolute risk, tracking error, or any desired blend of the two risk measures. An intuitive derivation is provided in "Appendix 1".

An alternative approach is presented in Harvey and Siddique (2000), which studies the impact of conditional skewness across securities on asset pricing models. It considers how much a particular security contributes to the skewness of a broad portfolio. In a large market decline driven by the onset of war, most equities would be hurt a lot while others might actually prosper (e.g., defense contractors). During the Global Financial Crisis, financial stocks were particularly impacted. Similarly in the current COVID-19 pandemic, airlines and hotels have been most strongly impacted, while many tech firms and pharma companies have done extremely 
well. This study concludes that the collective impact of "coskewness" on equity asset pricing is on the order of $3.6 \%$ return per annum on a typical market index portfolio, which is in the same ballpark as our above hypothetical discussion of the components of $R_{0}$.

\section{The last big piece of the puzzle: bankruptcy risk}

Given the foregoing discussion of co-skewness, it should be intuitive that firms that have larger risk of bankruptcy would contribute more highly to the potential for a market decline during the rare periods of severe economic stress. The correlation of possible failures between a particular firm and the other firms in the market can therefore be estimated as a source of "co-skewness." Again, the single period nature of the CAPM is an unrealistic assumption. In the CAPM, there are only two concepts of time, now and when the "single period" ends. It is assumed that assets that existed at the start of the period will exist at the end of the period.

Merton (1974) shows that bankruptcy risk can be described as an option where the volatility of a firm's asset value is the key input. In diBartolomeo (2010) an extended Merton model is used to show that investors price equities as if they do not exist in perpetuity, but rather have some built in expectation of a failure rate. Put simply, the volatility of firm assets can be approximated as the observed (or expected) absolute volatility of a firm's traded equity divided by the firms assets/equity ratio (at market value). An exact relation is available using Ito calculus. The assets/ equity ratio (market value) is equal to $(1+$ debt/equity). In essence, the probability of default for realistic cases is a "not but almost" linear function of the interaction of the volatility of a firm's assets and the firm's degree of financial leverage (debt/equity). To the extent that the debt/equity ratio is often explanatory of changes in the market value of equity (i.e., company profits are sensitive to interest rates) we will include both the debt/equity ratio and the historic value of equity volatility as factors to be estimated in our model. Since the debt/equity ratio of a firm at each moment in time is observable, investors would typically attribute their concerns about ex-ante bankruptcy probability to time-series variation of equity volatility rather than the well understood effect of financial leverage. For US equities over a sample period from 1992 through 2010, the typical half-life was on the order of 20 years, implying an annual failure rate around $3.5 \%$. Khan et al. (2016) both report excess annual returns for portfolios constructed to be more sustainable. diBartolomeo (2018) reports similar excess returns of around 3\% annually for portfolios that have been intentionally survivorship biased to include only firms that survived through a sample period of 25 years.
Supplementing these results are numerous papers on "low volatility" investing which assert that low volatility equities produce persistently positive excess returns. Such studies include Haugen and Baker (1991), and Blitz and Van Vliet (2007) which address global equities markets. Under the CAPM, there are two sources of risk at the firm level. The first is beta and the other is idiosyncratic risk. If total volatility contributes to bankruptcy losses, but the return associated with beta risk is upward sloping (positive SML slope) then the return to idiosyncratic risk at the firm level must be negative, while the CAPM assumes zero. One can speculate as to why investors do not appear to correctly price bankruptcy risk at the _rm level (i.e. price equities so as to generate a sufficiently positive return to fully compensate for this risk) but an obvious explanation is that the seminal valuation model for equities, the "dividend discount model", is normally taught in academic settings in the simplified form of Gordon and Shapiro (1956) in which it is assumed that equities always survive in perpetuity.

\section{Defining the change in functional form}

For our empirical testing, we first review the equity risk premia and factor alpha outcomes using a fundamental (endogenous) factor model. Using this equity factor risk model has a number of advantages. First, it has been in live, commercial use by institutional investors since the late 1980s, so more than 30 years of data is available. All data has been saved as it was at each moment in time, so there is no survivorship or look-ahead biases in the data. Analytical changes to the model have been minimal and do not impact the analysis here. The coverage universe of the model included all stocks traded on major US exchanges, including American Depository Receipts so as to provide coverage of the majority of large firms not domiciled in the USA. The model is based in the classic CAPM, with the alpha term subdivided into 66 "factor alphas" (11 unit normal style factors and 55 industries). Regression estimation of the factor beta and factor alpha values is weighted by the square root of capitalization which affords a balance between the influence of large cap stocks and the more numerous small cap stocks.

As noted in Grinold and Kahn (1993), models of this type have routinely been estimated since the 1970's with "generalized least squares" (GLS) regressions to address both the high propensity of outliers in financial market data and the potential for correlation of residuals given the nature of the independent variables. Larger enterprises naturally play a larger role in the overall economy and have more stable operations so there is a strong negative empirical relationship between the magnitude of the "net of factors" residual returns and capitalization. Weighting by square root provides very similar estimators to 
GLS procedures while being simpler and more transparent to practitioners. Such regressions typically involve large numbers of securities so even with weighting the condition statistics does not typically indicate problems with multicollinearity. One of the style factors is a rescaled range measure of total volatility which we will use as our proxy for bankruptcy risk and thus likely firm level contribution to the existence of higher moments in the returns of the market portfolio. This admittedly coarse approximation allows us to keep the model in a fully linear form consistent with Ross (1976). Applying the Merton method for bankruptcy evaluation is rooted in option theory, which necessarily involves nonlinear relations between risks and economic payoffs. In the original form, the model is expressed as

$R_{i t}=R_{f}+b_{i t}\left(R_{m t}-R_{f}\right)+\sum_{j=1}^{66} Z_{i j t} \alpha_{j t}+\epsilon_{i t}$

where

$b_{i t}=$ beta of security $i$ during period $t$

$Z_{i j t}=$ unit normal exposure of security $i$ to factor $j$ during period $t$

$\alpha_{j t}=$ alpha of factor $j$ during period $t$

$\epsilon_{i t}=$ residual return of security $i$ during period $t$

To test the ideas put forth herein, we reorder the terms of the model, and replace the classic CAPM construct with a modified version of the "zero beta" CAPM that incorporates higher moments ("short lottery" risk) and bankruptcy risk. In Equation $4, R_{0 t}$ represents the return associated with the investors persistent demand for equities. The second term represents the influence of absolute volatility as a proxy for bankruptcy risk at the individual firm. The third term represents the traditional concept of the Security Market Line. The summation over the set of sixty-six style factors and industry groups is a decomposition of Jensen's alpha, which we assert are real alphas having been appropriately estimated net of all three risk premia that are evident in the data.

$$
\begin{aligned}
& R_{i t}=\left[R_{0 t}+\left(Z_{i, v o l, t} a_{v o l, t}\right)\right] \\
& \quad+b_{i t}\left(R_{m t}-R_{0 t}\right)+\sum_{j=1}^{65} Z_{i j t} a_{j t}+e_{i t} \\
& R_{0 t}=R_{f t}+R_{h} \\
& \text { where } \\
& \quad R_{0 t}=\text { return to zero beta asset } \\
& \quad R_{h}=\text { incremental return for market level higher moments } \\
& Z_{i, v o l, t}=\text { exposure of security } i \text { to total volatility factor in } \\
& \text { period } t \\
& \quad \alpha_{v o l, t}=\text { alpha of total volatility factor in period } t
\end{aligned}
$$

\section{Empirical analysis}

Table 1 illustrates 360 months of factor return history of the original model from January 1990 through December 2019, with an estimation universe defined as all US traded equities with market capitalization over \$250 million at each moment in time. We choose to exclude firms with capitalization below this limit for several reasons. Institutional investors are generally unable to be shareholders of "micro-cap" firms as having insufficient market liquidity for large transactions. In addition, the US has regulatory reporting which require investors to publicly report significant share positions (e.g., greater than $5 \%$ of shares outstanding). Such disclosures are perceived as disadvantageous to sophisticated investors. As such, participation in very small firms is dominated by retail investors who are unlikely to be reliant on mathematically complex asset pricing models. It should be noted that large troubled firms routinely enter into "voluntary reorganization" which allows them to reduce their debt burden through the courts. This process also salvages some value for equity shareholders thereby keeping these firms in our data set.

There is a vast supply of research papers written on various permutations of how to define momentum in equity markets and the apparently related market outcomes. Many people would point to the seminal papers of Jegadeesh and Titman (1993, 2011). The most widely used definition of momentum comes from Carhart (1997), which uses a one-year sample period to measure the effect. The Carhart definition of momentum is frequently combined with the equity factors defined by Fama and French (1992). More recent studies include those of Novy-Marx $(2012,2015)$ which argue that price momentum is a manifestation of

Table 1 Monthly Factor Payoff History 1990-2019 Traditional CAPM

\begin{tabular}{lrlrrr}
\hline & Mean & StDev & \multicolumn{1}{l}{ T } & \multicolumn{1}{l}{ Min } & Max \\
\hline Market $\left(R_{m}-R_{f}\right)$ & 0.67 & 4.61 & 2.80 & -21.32 & 14.36 \\
Earnings/Price & 0.12 & 0.64 & 3.57 & -2.35 & 2.50 \\
Book/Price & -0.04 & 0.81 & -1.02 & -4.10 & 2.85 \\
Dividend Yield & 0.18 & 0.77 & 4.60 & -2.45 & 3.24 \\
Trading Activity & 0.04 & 1.17 & 0.72 & -4.40 & 6.83 \\
Momentum RS & 0.45 & 2.04 & 4.29 & -8.20 & 12.80 \\
Market Cap & -0.05 & 0.76 & -1.15 & -2.20 & 2.44 \\
EPS Variability & -0.12 & 0.51 & -4.37 & -2.61 & 1.68 \\
EPS Growth Rate & 0.01 & 0.62 & 0.41 & -2.86 & 2.08 \\
Revenue/Price & 0.08 & 0.82 & 1.92 & -2.77 & 3.08 \\
Debt/Equity & -0.03 & 0.79 & -0.80 & -4.59 & 9.57 \\
Price Volatility & -0.32 & 1.46 & -4.22 & -4.96 & 7.93 \\
\hline
\end{tabular}


momentum in the fundamental profitability of firms. Consistent with the published literature, we observe a large and positive equity risk premium over the risk free rate. A large positive magnitude alpha that is highly statistically significant is associated with the momentum measure in this formulation.

Similarly, there is a massive literature on the concept of "value" in equity investing. Notable related research include Graham and Dodd (1934), Basu (1977), Klarman (1991) and Fama and French (1992). There is a wide dispersion of metrics for "value" inclusive of earnings/price ratios, book value/price ratios, and dividend yield. The models also include a revenue/price ratio factor. While the mean alpha to the widely used valuation measure book/ price ratio is close to zero for the sample period, the four valuation-based factors combine for a $.34 \%$ per month average alpha that is again highly statistically significant in aggregate. There is a significant negative mean alpha to "earnings variability" (i.e., the negative of "quality"). In keeping with the prior discussion of total equity volatility as a proxy for bankruptcy risk, we expect and observe a large negative factor alpha that is highly significant.

While this data illustrates the large equity risk premium over the sample period, it does not illustrate the observed slope of the Security Market Line. To estimate a reasonable SML slope we constructed two portfolios, one which consisted of all equities in the universe at a moment in time on an equal weighted basis (i.e., monthly rebalancing) and a second portfolio consisting of the same equities but on a capitalization weighted basis. The two portfolios were then sub-divided into ten sub-portfolios by beta range. Using the attribution method of Brinson and Fachler (1985) we estimated the slope of the Security Market Line at around 1.6\%( $T=3)$ per annum for the capitalization weighted sub-samples and again 1.6\%( $T=3.6)$ for the equal weighted sub-samples. Pooling the two sets of sub-sample portfolios changes the relative weights of sub-samples, resulting in a change in the cross-sectional correlation of beta and subsequent returns. This effect increases the estimated annual SML slope to $1.8 \%(T=4)$. These values represent a monthly SML slope of about $.14 \%$ per month.

Subtracting the monthly mean of the SML slope (.14\%) from the mean of the market factor return $(.67 \%)$ we get a difference of .53\% per month, or just over $6 \%$ per annum as a remainder of the mean monthly return on the "zero beta" asset $\left(R_{o}\right)$. Under our framework, we cannot observe that the zero-beta return varies over time although it is almost certain it does as the confidence of investors ebbs and rises. However, we can simply choose what appears to be a reasonable constant value for $R_{h}$. We can then calculate the remainder of the problem (SML and factor alphas) conditional on our chosen value. We chose a tentative constant of $.35 \%$ per month based on the aforementioned results of Harvey and Siddique, Barro, Gabaix, as well as our own value of .41\% that arose from the previous hypothetical. We then recreated the entire model in the form of Equation 4. The revised results are presented in Table 2.

The two tables differ in that the equity risk premium of Table 1 has been replaced placed with the slope of the Security Market Line (SML) conditional on $R_{h}=.35 \%$ per month. It should be noted that we do not assert that the .35\% per month value is the correct value for this unobservable characteristic of the sample period. We use the $.35 \%$ per month as a reasonable estimate only to show how making this value nonzero materially impacts the interpretation of returns to the model factors. Other values in the range discussed are also plausible but results conditional on the choice of value are qualitatively similar. The mean monthly SML is now .32\% per month and appears to be not statistically significant. However, this low value for the $T$ statistic is an artifact that we have chosen to make the zero-beta return a constant since we cannot observe it's time series variation. This means that all of the unobservable variation in $R_{o}$ and the observable variation in the risk free rate are effectively being loaded into the variation of the SML, making it rather unfairly appear as not statistically significant. What we can conclude from all tests conducted is that the slope of the SML is upward and seems statistically significant in tests that do not exaggerate it's variation over time. As such, the idea of a "low beta" portfolio being advantageous is not demonstrated, as distinct from a "low absolute volatility" portfolio. We can infer from this juxtaposition that the returns associated with idiosyncratic risk at the individual firm level are substantially negative, consistent with prior expectations.

We have also changed the position of the factor alpha associated with absolute price volatility in Table 2 as a

Table 2 Monthly Factor Payoff History 1990-2019 Extended CAPM ( $R_{h}=.35 \%$ per month)

\begin{tabular}{lrlrrr}
\hline & Mean & StDev & \multicolumn{1}{l}{ T } & \multicolumn{1}{l}{ RMin } & Max \\
\hline SML & 0.32 & 4.87 & $1.23^{*}$ & -21.67 & 14.01 \\
Price Volatility & -0.21 & 1.25 & -3.22 & -4.42 & 5.10 \\
Earnings/Price & 0.13 & 0.74 & 3.30 & -2.40 & 3.40 \\
Book/Price & -0.03 & 0.89 & -0.73 & -4.39 & 2.75 \\
Dividend Yield & 0.10 & 0.79 & 2.40 & -3.61 & 2.75 \\
Trading Activity & -0.02 & 0.85 & -0.38 & -2.58 & 4.73 \\
Momentum RS & -0.01 & 1.71 & -0.09 & -11.23 & 6.58 \\
Log of Market Cap & -0.23 & 2.77 & -1.54 & -12.29 & 12.72 \\
EPS Variability & -0.12 & 0.59 & -3.75 & -2.59 & 2.35 \\
EPS Growth Rate & 0.01 & 0.99 & 0.28 & -4.72 & 4.86 \\
Revenue/Price & 0.07 & 0.75 & 1.70 & -3.10 & 2.61 \\
Debt/Equity & 0.18 & 1.70 & 2.00 & -2.34 & 20.15 \\
\hline
\end{tabular}


reminder that we now consider this effect as part of risk on which the remaining factor payoffs are conditional. The monthly factor alpha for price volatility is now $.21 \%$ per month and is highly statistically significant. It should be noted that both estimates of the mean factor alpha of .32\% and $.21 \%$ per month sum to annual values close to the $3 \%$ expectation described above. What is very different is that the factor alpha for Momentum essentially disappears, with a mean near zero. The factor alphas for the four valuation related factors now sum to $.26 \%$ per month $(T=2.56)$ and continues to be statistically significant. The factor alpha for the EPS Variability ("anti-quality") was the same in both frameworks at $-.12 \%$ annum and is highly significant in both as well.

In "Appendix 2", we present six additional tables illustrating the factor outcomes for both the original and revised models, broken into three decade-long subsamples (1990s, 2000s, 2010s). The changes in the model design brought about two very noteworthy changes in the factor outcomes in the 1990s. First, in the traditional model, the Momentum factor had an extremely strong performance with a monthly mean return of over $1 \%$ and low volatility. In essence, when viewed in the framework of the classic CAPM, the stocks that were "going up" kept going up which could be clearly associated with the "Tech Bubble" phenomenon that was observed in the US market. Under the revised model, the mean factor outcomes for Momentum were slightly negative but not statistically significant. The more nuanced structure of the revised model captured the extraordinary volatility of "Dot Com" stocks that were the equity subset that were the main contributors to the Momentum effects in the classic framework. The revised model also captured the very strong returns to financial leverage in this period (Debt/Equity) as key interest rates fell substantially through the 1990s with 3 month US Treasury Bill yields declining from $7.83 \%$ at the start of the decade to $5.81 \%$ at the close. The change in 5 year Treasury annual yields was also large falling from $7.87 \%$ to $6.5 \%$. Under such a material decline in interest rates, the superior risk-adjusted performance of levered firms should be intuitive, but was not observed in the classic framework.

The decade of the 2000s also produced intuitive results. There were two "large events" in this sub-sample, the collapse of the "Tech Bubble" at the onset of the decade and the Global Financial Crisis in the latter half of the period. Unsurprisingly, the factor outcomes for this period were very positive and statistically significant in both models with regard to three valuation measures, Earnings/ Price, Dividend Yield, and Revenue/Price. The popular Book Value/Price measure which is widely used in many academic studies was near zero and insignificant in both models. We attribute this fact to investor recognition of the irrelevance of book value to "tech" companies, and the distortions caused by government rescues of insolvent financial institutions during the GFC period. Other recent studies such as Goncalves and Leonard (2020) have also taken note of the empirical evidence of the reduced influence of Book/Price as an explanatory market variable. EPS Variability ("anti-quality") was significantly and nearly identically negative under both models for this decade. The Momentum factor outcomes were close to zero and insignificant under both models.

Our last sub-sample, the 2010s decade also had some interesting factor outcomes. The four valuation related factors were all either near zero or significantly negative under both models. In both models, the Momentum factor outcomes were positive at around .20\% per month and marginally statistically significant. Earnings Variability ("anti-quality") again had a significant negative mean under both models. Outcomes to the leverage (Debt/ Equity) were modestly negative but significant under both models.

\section{Conclusions}

We have proposed an extension of the "zero beta" CAPM where the magnitude of the return on the zero-beta asset arises from investor concern for rare, extreme events such as the current COVID-19 pandemic. This functional form provides for both a high equity risk premium and a smaller but positive slope to the Security Market Line. Our formulation also captures the differential risk of bankruptcy across individual firms. Over 30 years of empirical observations suggest that the larger part of the equity risk premium is associated with rare but extreme events. The CAPM view that idiosyncratic risk should carry no return is refuted. We expect and find a negative return arising from bankruptcy risk at the firm level, thereby contributing to co-skewness at the market level.

"Smart beta" strategies that are predicated on historical excess returns alone without the context of how risks influence asset pricing are ill advised. In the context of the revised model, the long-term alpha mean associated with various equity factors on which strategies are often predicated (e.g., value, momentum, size, etc.) change significantly. In the new formulations over the sample period of 2000-2020, the mean monthly alpha associated with both value and momentum remain positive but become smaller in magnitude and are statistically insignificant. Monthly alpha averages for size, leverage and earnings variability are all negative and statistically significant $(P>90 \%)$. Doing asset pricing in a nuanced fashion that more richly captures the risk characteristics of firms is clearly preferable as it leads to an appropriate mechanism for investors 
to judge factor returns on a risk-adjusted basis, thereby allowing investors to achieve real alpha.

\section{Appendix 1}

We start with a "growth optimal" investor whose only objective is to maximize their long-term geometric mean return. The usual objective function is

$U=R-\lambda * s^{2}$

For a growth optimal investor who only cares about maximizing the future geometric mean return, $\lambda=.5$ or $\frac{1}{2}$ assuming all units are in decimals. To remove the potential for $\lambda=0$, where we would have to restate all return distributions as risk neutral probabilities, we will rewrite the expression with the tradeoff parameter in the denominator and also convert to annual percentage return units.

$U=R-\frac{s^{2}}{T}$

For the growth optimal case $T=200$. The question is, what is the appropriate scalar $T$ for an investor less tolerant of risk? We will infer this risk tolerance from the boundary condition we call the "Maximum Loss Fraction." Let's work through a simple example, where the existing portfolio has expected annual return $R=8$, and annual return standard deviation $s=12$. Implicit in choosing a portfolio of a particular volatility level (e.g., 12\%) is the idea that the investor doesn't want to put all their money at risk, just some of it per Wilcox (2003). A reasonable expectation for the annual maximum loss fraction $M$ of the portfolio value would be where $Z$ is your choice of $Z$-score for a worst case scenario (e.g., a 3.5 standard deviation event).

$M=(Z * s)-R$

$M=3.5 * 12-8=34$

So, we're only willing to put $34 \%$ (.34) of the portfolio at risk (implicit $T=200$ ) which means that the other part of the portfolio must be riskless (implicit $T=0$ ).

$T=.34 * 200+(1-.34) * 0=68$

If we divide $T$ through by $s$, we obtain $\frac{68}{12}=5.67$ (about six). Since both $R$ and $s$ are first order functions of security weights, their relation should also be linear. Now we can express our objective function as:

$U=\frac{R-s^{2}}{5.67 * s}$

$U=R-\left(\frac{1}{5.67}\right) * s$

So our tradeoff value $K$ between return and standard deviation is about $\frac{1}{6}$. For a broad range of empirical cases, the $\frac{1}{6}$ relationship holds rather nicely. For tracking error cases rather than absolute volatility, it might be reasonable to use $Z=3, R=0$, which renders exactly $\frac{1}{6}$.

\section{Appendix 2}

See Tables 3, 4 and 5 .

Table 3 Years 1990-1999

\begin{tabular}{lrlrlrlrrrrrr}
\hline & Mean & StDev & T & Min & Max & & Mean & StDev & T & Min & Max \\
\hline Original CAPM & & & & & & Extended CAPM & & & & \\
Market $\left(R_{m}-R_{f}\right)$ & 0.95 & 4.14 & 2.51 & -17.95 & 10.71 & SML & 0.53 & 4.78 & 1.22 & -20.59 & 12.58 \\
Price Volatility & 0.03 & 1.06 & 0.32 & -2.74 & 3.51 & Price Volatility & -0.03 & 0.89 & -0.40 & -3.43 & 3.53 \\
Earnings/Price & 0.06 & 0.59 & 1.20 & -2.52 & 2.00 & Earnings/Price & 0.09 & 0.81 & 1.16 & -2.40 & 3.40 \\
Book/Price & 0.17 & 0.72 & 2.55 & -1.59 & 2.69 & Book/Price & 0.04 & 0.83 & 0.59 & -3.01 & 2.75 \\
Dividend Yield & 0.21 & 0.89 & 2.58 & -1.61 & 3.59 & Dividend Yield & 0.16 & 0.99 & 1.78 & -3.61 & 2.75 \\
Trading Activity & 0.08 & 1.66 & 0.54 & -5.12 & 8.75 & Trading Activity & 0.09 & 0.81 & 1.27 & -2.45 & 3.95 \\
Momentum RS & 1.13 & 2.07 & 5.97 & -3.81 & 9.30 & Momentum RS & -0.22 & 1.86 & -1.30 & -11.23 & 6.58 \\
Log of Market Cap & 0.00 & 0.87 & 0.02 & -2.17 & 2.59 & Log of Market Cap & -0.37 & 4.60 & -0.87 & -12.29 & 12.72 \\
EPS Variability & 0.02 & 0.53 & 0.35 & -1.33 & 1.68 & EPS Variability & -0.03 & 0.56 & -0.62 & -1.87 & 2.35 \\
EPS Growth Rate & 0.07 & 0.57 & 1.29 & -1.67 & 1.81 & EPS Growth Rate & 0.06 & 1.44 & 0.43 & -4.72 & 4.86 \\
Revenue/Price & 0.09 & 0.86 & 1.15 & -3.25 & 2.01 & Revenue/Price & -0.05 & 0.54 & -1.12 & -2.41 & 1.43 \\
Debt/Equity & -0.06 & 0.78 & -0.84 & -2.17 & 5.30 & Debt/Equity & 0.64 & 2.77 & 2.53 & -1.31 & 20.15 \\
\hline
\end{tabular}


Table 4 Years 2000-2009

\begin{tabular}{lrlrlrlrrrrr}
\hline & Mean & StDev & \multicolumn{1}{l}{ T } & Min & Max & & Mean & StDev & T & Min & Max \\
\hline Original $C A P M$ & & & & & & Extended CAPM & & & \\
Market $\left(R_{m}-R_{f}\right)$ & 0.16 & 5.50 & 0.31 & -21.3 & 14.35 & SML & -0.08 & 5.56 & -0.16 & -21.67 & 14.01 \\
Price Volatility & -0.32 & 1.86 & -1.90 & -5.17 & 2.42 & Price Volatility & -0.29 & 1.55 & -2.04 & -4.42 & 5.10 \\
Earnings/Price & 0.31 & 0.83 & 4.09 & -2.59 & 2.66 & Earnings/Price & 0.33 & 0.77 & 4.63 & -2.39 & 2.24 \\
Book/Price & -0.05 & 1.10 & -0.47 & -4.89 & 1.88 & Book/Price & 0.02 & 1.01 & 0.24 & -4.39 & 2.65 \\
Dividend Yield & 0.15 & 0.70 & 2.31 & -2.47 & 4.69 & Dividend Yield & 0.11 & 0.70 & 1.75 & -2.48 & 1.79 \\
Trading Activity & -0.19 & 1.03 & -1.99 & -2.66 & 4.14 & Trading Activity & -0.16 & 1.02 & -1.68 & -2.58 & 4.73 \\
Momentum RS & 0.06 & 1.89 & 0.33 & -8.39 & 1.90 & Momentum RS & 0.00 & 1.88 & -0.03 & -8.47 & 4.06 \\
Log of Market Cap & -0.28 & 0.93 & -3.24 & -3.13 & 1.64 & Log of Market Cap & -0.23 & 1.06 & -2.33 & -4.50 & 4.29 \\
EPS Variability & -0.24 & 0.73 & -3.58 & -2.58 & 2.90 & EPS Variability & -0.24 & 0.74 & -3.55 & -2.59 & 1.63 \\
EPS Growth Rate & -0.06 & 0.78 & -0.81 & -2.82 & 5.63 & EPS Growth Rate & -0.05 & 0.78 & -0.64 & -2.77 & 2.93 \\
Revenue/Price & 0.16 & 1.06 & 1.67 & -3.08 & 1.69 & Revenue/Price & 0.17 & 1.03 & 1.80 & -3.10 & 2.61 \\
Debt/Equity & -0.07 & 0.69 & -1.16 & -2.99 & 10.17 & Debt/Equity & -0.05 & 0.63 & -0.90 & -2.34 & 1.68 \\
\hline
\end{tabular}

Table 5 Years 2010-2019

\begin{tabular}{lrlrlrlrrrrr}
\hline & Mean & StDev & \multicolumn{1}{l}{ T } & Min & Max & & Mean & StDev & T & Min & Max \\
\hline Original CAPM & & & & & & Extended CAPM & & & \\
Market $\left(R_{m}-R_{f}\right)$ & 0.90 & 4.14 & 2.38 & -10.49 & 13.09 & SML & 0.54 & 4.13 & 1.44 & -10.84 & 12.74 \\
Price Volatility & -0.36 & 1.21 & -3.22 & -3.66 & 3.29 & Price Volatility & -0.29 & 1.22 & -2.59 & -3.63 & 3.36 \\
Earnings/Price & -0.06 & 0.54 & -1.17 & -1.41 & 1.40 & Earnings/Price & -0.04 & 0.54 & -0.76 & -1.37 & 1.41 \\
Book/Price & -0.20 & 0.80 & -2.69 & -2.18 & 2.34 & Book/Price & -0.17 & 0.80 & -2.33 & -2.15 & 2.35 \\
Dividend Yield & 0.06 & 0.64 & 1.02 & -1.72 & 1.88 & Dividend Yield & 0.02 & 0.64 & 0.37 & -1.77 & 1.84 \\
Trading Activity & -0.01 & 0.65 & -0.14 & -1.31 & 1.97 & Trading Activity & 0.01 & 0.65 & 0.21 & -1.29 & 1.98 \\
Momentum RS & 0.20 & 1.28 & 1.72 & -3.54 & 4.05 & Momentum RS & 0.19 & 1.27 & 1.63 & -3.60 & 4.01 \\
Log of Market Cap & -0.07 & 0.71 & -1.04 & -1.92 & 1.79 & Log of Market Cap & -0.07 & 0.71 & -1.10 & -1.91 & 1.78 \\
EPS Variability & -0.08 & 0.40 & -2.24 & -1.25 & 0.86 & EPS Variability & -0.07 & 0.39 & -2.03 & -1.19 & 0.88 \\
EPS Growth Rate & 0.04 & 0.51 & 0.86 & -1.78 & 1.51 & EPS Growth Rate & 0.04 & 0.50 & 0.80 & -1.78 & 1.50 \\
Revenue/Price & 0.08 & 0.58 & 1.43 & -1.44 & 1.33 & Revenue/Price & 0.08 & 0.58 & 1.57 & -1.42 & 1.36 \\
Debt/Equity & -0.08 & 0.42 & -2.19 & -1.85 & 1.07 & Debt/Equity & -0.06 & 0.42 & -1.68 & -1.82 & 1.10 \\
\hline
\end{tabular}

\section{References}

Barro, Robert. 2005. Rare Events and the Equity Premium. NBER Working Paper Number 11310.

Basu, S. 1977. Investment Performance of Common Stocks in Relation to the Price-Earnings Ratios: A Test of the Efficient Markets Hypothesis. Journal of Finance 32 (3): 663-682.

Black, Fischer. 1972. Capital Market Equilibrium with Restricted Borrowing. Journal of Business 45 (3): 444-455.

Blitz, David, and Pim van Vliet. 2007. The Volatility Effect. Journal of Portfolio Management 34 (1): 102-113.

Brinson, Gary, and Nimrod Fachler. 1985. Measuring Non-US Equity Portfolio Performance. Journal of Portfolio Management 11 (3): $\mathrm{x}$.

Carhart, Mark. 1997. On Persistence in Mutual Fund Performance. Journal of Finance 52 (1): 57-82.

Cornish, E.A., and R.A. Fisher. 1938. Moments and Cumulants in the Specification of Distributions. Review of the International Statistical Institute 5 (4): 307-320.
diBartolomeo, Dan. 1988. Computers and the Crash: Did the Machines Really Do It?, Computer Update.

diBartolomeo, Dan. 2013. Low Volatility Investing: Anomaly or Algebraic Artifact, Northfield Asia Seminar.

diBartolomeo, Dan. 2010. Equity Risk, Credit Risk, Default Correlation, and Corporate Sustainability. Journal of Investing 19 (4): 128-133.

diBartolomeo, Dan. 2018. Considerations Relevant to Sustainable Investing, Northfield News https://www.northinfo.com/Docum ents/848.pdf.

Dimson, E., P. Marsh, and M. Staunton. 2014. Emerging Market Revisited. Credit Suisse Research Institute: Global Investment Returns Yearbook.

Fama, Eugene. 1970. Efficient Capital Markets: A Review of Theory and Empirical Work. Journal of Finance 25 (3): 383-417.

Fama, E., and K. French. 1992. The Cross-Section of Expected Stock Returns. Journal of Finance 47 (2): 427-465.

Frazzini, Andrea and Lasse H. Pedersen. 2011. Betting Against Beta, Swiss Finance Institute Research Paper Number 12-17. 
Gabaix, Xavier. 2012. Variable Rare Disasters: An Exactly Solved Framework for Ten Puzzles in Macro-Finance. Quarterly Journal of Economics 127 (2): 645-700.

Goncalves, Andrei and Gregory Leonard. 2020. The Fundamental-toMarket Ratio and the Value Premium Decline, University of North Carolina Working Paper.

Gordon, M.J., and Eli Shapiro. 1956. Capital Equipment Analysis: The Required Rate of Profit. Management Science 3 (1): 102-110.

Graham, Benjamin, and David Dodd. 1934. Security Analysis. New York: McGraw-Hill.

Grinold, Richard. 1993. Is Beta Dead Again? Financial Analyst Journal 49 (4): 28-34.

Grinold, Richard, and Ronald Kahn. 1995. Active Portfolio Management (1st edition), page 59. Chicago: Probus Publishing.

Harvey, C., and A. Siddique. 2000. Conditional Skewness in Asset Pricing Tests. Journal of Finance 55 (3): 1263-1295.

Haugen, Robert, and Nardin Baker. 1991. The Efficient Market Inefficiency of Capitalization-Weighted Stock Portfolios. Journal of Portfolio Management 19 (3): 35-40.

Jacobs, Bruce I., and Kenneth Levy. 2012. Leverage Aversion and Portfolio Optimality. Financial Analysts Journal 68 (5): 89-94.

Jegadeesh, N., and S. Titman. 1993. Returns to Buying Winners and Selling Losers: Implications for Stock Market Efficiency. Journal of Finance 48 (1): 65-91.

Jegadeesh, N., and S. Titman. 2011. Momentum. Annual Review of Financial Economics 3.

Jensen, Michael C. 1967. The Performance of Mutual Funds in the Period 1945-1964 (May 1, 1967). Journal of Finance 23 (2): 389-416.

Khan, Mozaffar, George Serafeim, and Aaron Yoon. 2016. Corporate Sustainability: First Evidence on Materiality. The Accounting Review 91 (6): 1697-1724.

Klarman, Seth. 1991. Margin of Safety: Risk Averse Value Investing Strategies for the Thoughtful Investor. New York: Harper Business.

Levy, H., and H.M. Markowitz. 1979. Approximating Expected Utility by a Function of Mean and Variance. American Economic Review 69 (3): 308-317.

Markowitz, Harry. 1952. Portfolio Selection. Journal of Finance 7 (1): $77-91$.

Markowitz, Harry, and Erik van Dijk. 2003. Single-Period Mean-Variance Analysis in a Changing World. Financial Analyst Journal 59 (2): 30-44.

Merton, Robert. 1974. On the Pricing of Corporate Debt: The Risk Structure of Interest Rates. Journal of Finance 29 (2): 449-470.

Merton, Robert. 1973. An Intertemporal Capital Asset Pricing Model. Econometrica 41 (5): 867-887.
Novy-Marx, R. 2012. Is Momentum Really Momentum? Journal of Financial Economics 103 (3): 429-453.

Novy-Marx, R. 2015. Fundamentally, Momentum is Fundamental Momentum, NBER Working Paper No. 20984.

Ross, Steven. 1976. The Arbitrage Theory of Capital Asset Pricing. Journal of Economic Theory 13 (3): 383-402.

Siegel, Jeremy. 2014. Stocks for the Long Run: The Definitive Guide to Financial Market Returns and Long-Term Investment Strategies (5th ed.), New York: McGraw-Hill.

Sharpe, William F. 1964. Capital Asset Prices: A Theory of Market Equilibrium under Conditions of Risk. Journal of Finance 19 (3): 425-442.

Wilcox, Jarrod. 2003. Harry Markowitz and the Discretionary Wealth Hypothesis. Journal of Portfolio Management 29 (3): 58-65.

Publisher's Note Springer Nature remains neutral with regard to jurisdictional claims in published maps and institutional affiliations.

Christopher Kantos is a Director in EMEA, formerly a senior equity risk analyst at Northfield. Joining in 2007, Chris has responsibility for the analytical estimation and production of equity risk models at the firm. He is active in numerous investment industry associations including the Chicago Quantitative Alliance, the International Association for Quantitative Finance, and the London Quant Group. Chris has done public presentations in seven countries including the LQG, the CQA, the IAQF and Northfield events. Mr. Kantos is a magna cum laude graduate of Tufts University in Computer Engineering.

Dan diBartolomeo is President and founder of Northfield Information Services, Inc. He sits on boards of numerous industry organizations include the International Association for Quantitative Finance (IAQF) and Chicago Quantitative Alliance (CQA), and is a director for the Professional Risk Managers' International Association (PRMIA), Quantitative Work Alliance for Applied Finance, Education and Wisdom (QWAFAFEW) and in the past president of the Boston Economic Club. He has a long list of publications including books, book chapters and research articles published in professional journals. In addition, Dan spent eight years as a Visiting Professor at Brunel University, and has been admitted as an expert witness in litigation matters regarding investment management practices and derivatives in both US federal and state courts. 